\title{
Coated Pit
}

National Cancer Institute

\section{Source}

National Cancer Institute. Coated Pit. NCI Thesaurus. Code C13366.

Specialized depressions on the cell surface involved in receptor-mediated endocytosis;

the visible proteinaceous layer on the cytosolic side of the depression provides the coated appearance. 